\title{
A EXPANSÃO DOS SISTEMAS AVALIATIVOS E A TEORIA CRÍTICA: UM DIÁLOGO (IM) PERTINENTE
}

\author{
LA EXPANSIÓN DE LOS SISTEMAS EVALUADORES Y LA TEORÍA CRÍTICA: UN \\ DIÁLOGO (IN) PERTINENTE
}

THE EXPANSION OF EVALUATION SYSTEMS AND THE CRITICAL THEORY: A (IM) PERTINENT DIALOGUE

\author{
Andréia Nunes MILITÃO ${ }^{1}$ \\ Andréia da Cunha Malheiros SANTANA ${ }^{2}$ \\ Fabio PERBONI ${ }^{3}$
}

RESUMO: Este artigo objetiva refletir sobre a expansão dos sistemas de avaliação e articulála ao conceito de educação emancipatória da Teoria Crítica de Sociedade. Os dados quantitativos das avaliações no cenário atual reforçam a competição entre as escolas, além de uma visão tecnicista do conhecimento. O modelo avaliativo proposto pelo Estado reflete um modelo calcado em uma lógica gerencial e técnica, o que contraria as bases da teoria crítica. Trata-se de uma pesquisa qualitativa, de cunho bibliográfico, com a fundamentação teórica embasada em Adorno (1995), Adorno e Horkheimer (1985), Afonso (2007), Gomes (2010) e outros. A teoria crítica prega a importância da educação como sendo algo capaz de humanizar e conscientizar o ser humano frente às injustiças sociais, e este conhecimento não pode ser medido por uma avaliação externa.

PALAVRAS-CHAVE: Avaliação externa. Qualidade da educação. Emancipação. Teoria crítica.

RESUMEN: El artículo tiene por objetivo reflexionar sobre la expansión de los sistemas de evaluación y articula al concepto de educación emancipadora de la Teoría Crítica de Sociedad. Los datos cuantitativos de las evaluaciones en el escenario actual refuerzan la competición entre las escuelas, además de una visión tecnicista del conocimiento. El modelo evaluativo propuesto por el Estado refleja un modelo basado en una lógica gerencial y técnica, lo que contraria las bases de la teoría crítica. Se trata de una investigación cualitativa, de cuño bibliográfico, con la fundamentación teórica basada en Adorno (1995), Adorno y Horkheimer (1985), Afonso (2007), Gomes (2010) y otros. La teoría crítica plantea la importancia de la educación como algo capaz de humanizar y concientizar el ser humano frente a las injusticias sociales, y este conocimiento no se puede medir por una evaluación externa.

\footnotetext{
${ }^{1}$ Universidade Estadual de Mato Grosso do Sul (UEMS), Dourados - MS - Brasil. Docente do Programa de Pósgraduação em Educação. E-mail: andreiamilitao@uems.br

${ }^{2}$ Universidade Estadual de Londrina (UEL), Londrina - PR - Brasil. Professor Adjunto. Coordenadora do Programa de Mestrado Profissional Profletras. E-mail: andreiacunhamalheiros@gmail.com.

${ }^{3}$ Universidade Federal da Grande Dourados (UFGD), Dourados - MS - Brasil. Docente do Programa de PósGraduação em Educação. E-mail: fabioperboni@ufgd.edu.br

RIAEE - Revista Ibero-Americana de Estudos em Educação, Araraquara, v. 14, n. esp. 4, p. 2046-2056, dez., 2019. E-ISSN: $1982-5587$. DOI: https://doi.org/10.21723/riaee.v14iesp.4.12927 
PALABRAS CLAVE: Evaluación externa. Calidad de la educación. Emancipación. Teoría crítica.

ABSTRACT: This article aims to reflect on the expansion of evaluation systems and to articulate it to the concept of emancipatory education of the Critical Theory of Society. The quantitative data of the evaluations in the current scenario reinforce the competition between the schools, besides a technicist view of the knowledge. The evaluative model proposed by the State reflects a model based on a managerial and technical logic, which contradicts the bases of critical theory. This is a qualitative, bibliographical research, with the theoretical foundation based on Adorno (1995), Adorno and Horkheimer (1985), Afonso (2007), Gomes (2010) and others. Critical theory preaches the importance of education as capable of humanizing and making human beings aware of social injustices, and this knowledge cannot be measured by external evaluation.

KEYWORDS: External evaluation. Education quality. Emancipation. Critical theory.

\section{Introdução}

O presente texto deriva de estudos sobre a avaliação externa dos sistemas públicos da educação básica brasileira. Propõe como recorte a análise da pertinência dos conceitos da teoria crítica para compreender os efeitos da ampliação dos sistemas avaliativos sobre o conceito de qualidade educacional.

Assume-se como pressuposto que a teoria crítica se caracteriza pela defesa da emancipação e do comportamento crítico em detrimento da teoria tradicional, marcada por uma pretensa neutralidade científica. Para tanto, ampara-se nas indagações formuladas por Gomes (2010) ao relacionar a teoria crítica e a educação política: "Que lugar ainda restaria para a 'esfera pública', se as 'políticas' continuarem a expressar muito mais os interesses privados do que os efetivamente públicos?” (GOMES, 2010, p. 287).

Observa-se na atualidade um movimento crescente em favor da ampliação da oferta educacional, paralelamente ao crescimento dos níveis de escolarização. Neste contexto, para além do discurso a favor da liberdade e da democratização, assiste-se a processos efetivos de valorização dos aspectos individuais em detrimento dos mecanismos que envolvem o bem comum como um de seus objetivos.

Conforme destaca Gomes (2010, p. 287), a “privatização dos mecanismos de controle ideológico da informação tem contribuído cada vez mais para que haja a intensificação daquilo que Adorno e Horkheimer, em 1947, denominaram de Indústria Cultural”. Temos, portanto, 
uma invasão do privado sobre o público, com fortes movimentos que vinculam a ideia de qualidade da formação apenas à dimensão técnico-instrumental, possível de ser aferida quantitativamente.

No atual cenário de complexidade das sociedades contemporâneas, vários são os fatores que contribuem para o agravamento da crise social. O esvaziamento da esfera pública e o consequente distanciamento da sociedade civil dos temas eminentemente sociais e humanos são sintomas que evidenciam a crise de uma das dimensões vitais da sociedade, a política. A esse respeito, as reflexões de Theodor Adorno sobre a educação, pensadas no contexto mais amplo de uma sociedade em que prevalece a racionalidade instrumental, o poder ideológico da indústria cultural e a conversão da Bildung (formação cultural) em Halbbildung (semiformação), não deixam dúvidas quanto aos limites do processo formativo atual (GOMES, 2010, p. 286).

Em detrimento de uma perspectiva crítica da cultura, que teria o papel de garantir a emancipação, se reforçam mecanismos ligados à ideologia dominante voltada para a adaptação e o conformismo. Segundo Adorno e Horkheimer (1985), a Indústria Cultural ${ }^{4}$ impossibilita a formação de indivíduos autônomos, capazes de julgar e decidir conscientemente.

\begin{abstract}
A atrofia da imaginação e da espontaneidade do consumidor de hoje não tem necessidade de ser explicada em termos psicológicos. Os próprios produtos, desde o mais típico, o filme sonoro, paralisam aquelas capacidades pela sua própria constituição objetiva. Eles são feitos de modo que sua apreensão exige, por um lado, rapidez de percepção, capacidade de observação e competência específica, e por outro são feitos de modo a vetar, de fato, a atividade mental do espectador, se ele não quiser perder os fatos que rapidamente se desenrolam à sua frente. É uma tensão tão automática que não há sequer necessidade de ser atualizada a cada passo para que reprima a imaginação (ADORNO; HORKHEIMER, 1985, p. 119).
\end{abstract}

Com os avanços da revolução industrial, do comércio e do capitalismo, os avanços tecnológicos se aprofundaram e foram utilizados para contribuir com o universo do consumo; ao refletirmos sobre o contexto educacional, é possível afirmar que as avaliações transmitem a impressão de serem alternativas modernas para avaliar a educação de modo objetivo, mas na verdade o que elas estão definindo são padrões de qualidade e promovendo um estreitamento dos currículos, num processo que determina quais são os conhecimentos válidos e aqueles que são dispensáveis. Evidencia-se que uma educação emancipatória deixa de ser prioridade, uma vez que as práticas escolares são direcionadas para atingir resultados mensuráveis, por meio

${ }^{4} \mathrm{O}$ termo Indústria Cultural substituiu a expressão "cultura de massa”. Ele foi criado por Adorno e Horkheimer em 1977. Uma cultura que antes era criada pelo povo passa a ser uma cultura imposta por poderes políticos e industriais da época e se estenderam até os dias de hoje, segundo Adorno e Horkheimer (1985).

RIAEE - Revista Ibero-Americana de Estudos em Educação, Araraquara, v. 14, n. esp. 4, p. 2046-2056, dez., 2019. E-ISSN: $1982-5587$. 
das avaliações que em sua maioria se restringe a medir a proficiência dos estudantes em conteúdos de matemática e de língua portuguesa.

Abandona-se, assim, qualquer pretensão de uma emancipação entendida como processo de "conscientização", definida por Maar (2003, p. 472) como a "reflexão racional pela qual o que parece ordem natural, 'essencial' na sociedade cultural, decifra-se como ordem socialmente determinada em dadas condições da produção real efetiva da sociedade".

\section{As Avaliações Externas e em Larga Escala e a Qualidade da Educação}

A sociedade contemporânea apesenta-se marcada pela tecnologia, pela fluidez e pela transitoriedade dos conhecimentos. Nesse mosaico construído cotidianamente pelo homem, poucas são as certezas nas quais podemos crer, e uma delas chama muita atenção: a educação. Não há uma sociedade que não se preocupe com o tema: mesmo que de modo diferente, todas atentam-se para educar os seus jovens; não há um político que não a insira na sua campanha; não há um economista que não calcule o quanto custa cada aluno do sistema, não há um educador que não reivindique mais investimento para a área. Assim, a educação é assunto prioritário até mesmo para os bancos, vide o papel do Banco Mundial na educação. A busca por uma educação de qualidade possibilitou o surgimento dos sistemas avaliativos, tal como anunciado pela Constituição Federal de 1988 e reforçado pela Lei de Diretrizes e Bases da Educação (LDB), nº 9.394/96, que explicitou a função do Estado:

Art. $9^{\circ}$ A União incumbir-se-á de:

$\mathrm{V}$ - coletar, analisar e disseminar informações sobre a educação; VI - assegurar processo nacional de avaliação do rendimento escolar no ensino fundamental, médio e superior, em colaboração com os sistemas de ensino, objetivando a definição de prioridades e a melhoria da qualidade do ensino;

VII - baixar normas gerais sobre cursos de graduação e pós-graduação;

VIII - assegurar processo nacional de avaliação das instituições de educação superior, com a cooperação dos sistemas que tiverem responsabilidade sobre este nível de ensino (BRASIL, 1996, grifo nosso).

A partir da criação da LDB/1996, os sistemas de ensino passaram a ser alvo de uma série de processos externos de avaliação, como meio de assegurar a qualidade da educação oferecida; mas como avaliar a qualidade da educação? O que significa uma avaliação de qualidade? Autores como Dourado e Oliveira (2009) e Rothen, Tavares e Santana (2015), ao discutirem tal temática, sob diferentes perspectivas, constataram que não se trata de algo simples, facilmente mensurável, pois o conceito de qualidade envolve uma discussão mais 
ampla tanto da sociedade que a propaga, como do momento histórico no qual tal discurso é disseminado; diferentes grupos podem empregar o termo com acepções e objetivos diversos. As discussões sobre a temática da qualidade não levaram em conta as diferentes concepções de educação, nem tampouco as finalidades desta, apenas enfatizaram a relação custo-benefício e a necessidade de divulgação dos resultados, por isso a valorização dos índices de evasão, repetência e exclusão.

A educação passou a ser vista como um serviço, e não como um direito, e a escola como uma organização, não como uma instituição. A escola concebida como uma organização privilegiou a avaliação externa em diferentes níveis de ensino, enfocando a competitividade entre as escolas e/ou entre os professores, como se "[...] a qualidade fosse produto da própria competição e não de uma construção coletiva" (FREITAS, 2004, p. 148).

Vivemos aquilo que Afonso (2007) chamou de "obsessão avaliativa"; para ele, os antigos exames nacionais, agora chamados de avaliações externas, foram retomados e reatualizados, o sistema capitalista passou a ver vantagens na hierarquização dos indivíduos através destes exames, pois estes propagam a ideia de serem meritocráticos e neutros.

Os princípios do capitalismo estão influenciando a educação e produzem, de acordo com Adorno, uma cultura de massa que padroniza o ensino e a formação do indivíduo, promovendo a alienação da consciência dos estudantes diante da sociedade; neste cenário, a educação é o único instrumento contra a barbárie. A avaliação tem sido utilizada para coisificar a própria escola. Para o autor, as avaliações externas continuam:

[...] a ser um dispositivo de controlo central por parte do Estado, relativamente ao que se ensinava (e como se ensinava) nas escolas públicas, e, simultaneamente, promover pressões competitivas entre os estabelecimentos de ensino públicos (ou entre estabelecimentos públicos e privados), induzindo, desta forma, um efeito de concorrência e hierarquização através da publicitação e divulgação dos resultados escolares dos estudantes (rankings), os quais deveriam, supostamente, apoiar a livre escolha educacional por parte dos pais, transformados, entretanto, em clientes ou consumidores da educação escolar (AFONSO, 2007, p. 14).

Este processo de transformação/coisificação do ser humano tende a torná-lo cada vez mais competitivo, menos solidário e mais técnico. Nesta ótica, a qualidade aparece como sinônimo de racionalidade instrumental, há uma supervalorização de indicadores quantitativos sem se levar em conta os atores envolvidos, os diferentes contextos educacionais e as demais políticas públicas voltadas para a educação. A avaliação externa não se preocupa com as realidades locais, nem busca encontrar formas para que todos atinjam a aprendizagem esperada. O seu objetivo é medir o desempenho cognitivo deixando de lado todo o contexto no qual estes 
sujeitos estão inseridos; desta forma, o discurso da qualidade propagado por estas avaliações tem servido para promover a elitização e meritocracia para a escola, reforçando a exclusão.

A associação dos resultados educacionais aos resultados econômicos tem sido recorrente para validar ingerências no campo pedagógico, notadamente, nos processos pedagógicos. Por outro lado, "os resultados das avaliações não servem ao diagnóstico das fragilidades do processo educacional e à proposição de melhorias. Ao contrário, alimentam a desconfiança sobre a educação pública e ampliam as propostas de intervenção e controle sobre a mesma" (AFONSO, 2007, p. 14).

Afonso (2007) defende que uma escola pública de qualidade deve ser democrática e propiciar diversas possibilidades de atingir a aprendizagem. A qualidade não pode ser só científica, medida por uma avaliação no final de um período, deve ser pedagógica e democrática. A criação de diversos processos avaliativos não tem acompanhado uma melhoria do ensino. O surgimento do "Estado Avaliador"5 tem se legitimado como um retrocesso político, porque valorizou técnicas positivistas e quantitativas e desvalorizou os processos educativos e sociais. Para Dias Sobrinho (2002, p. 28), no Estado Avaliador, “[...] prevalece a lógica de controle e da racionalidade orçamentária", legitimando o uso dos resultados das avaliações para justificar ou reduzir os investimentos em determinado nível de ensino.

Para superar o papel de controle exercido pelos sistemas de avaliação, torna-se necessário avaliar os próprios sistemas avaliativos, identificar quais são seus pontos fortes e fracos e, a partir deles, promover o diálogo entre os resultados alcançados e a escola. Somente com esta articulação será possível promover uma educação emancipatória e igualitária.

Ao esquadrinhar as origens do Sistema de Avaliação da Educação Básica (SAEB), localizamos sua formulação em experiências que se ampliaram a partir do final da década de 1980, chegando ao cenário atual de consolidação das práticas em vários sistemas de educação básica. Freitas (2007, p. 17) situa:

[...] o início do projeto de pesquisa sobre avaliação do rendimento de alunos de escolas de primeiro grau da rede pública. ... ele teria surgido do interesse do então ministro da Educação, Hugo Napoleão, em criar, por meio do INEP, um programa externo de avaliação do ensino de primeiro grau [fundamental], com função de subsidiar as secretarias.

${ }^{5}$ A expressão "Estado Avaliador” foi criada por Guy Neave (1988) para designar um Estado que associa o controle exercido por ele a estratégias de autonomia e autorregulação das instituições. É difícil precisar uma data para o surgimento do Estado Avaliador, uma vez que ele engloba muitas ações que, aparentemente, são isoladas, mas que estão articuladas à construção de uma ideia-chave central. No entanto, para efeito de situar o Estado Avaliador no panorama das mudanças acontecidas na educação, podemos pensar na década de 1980 como um marco inicial. RIAEE - Revista Ibero-Americana de Estudos em Educação, Araraquara, v. 14, n. esp. 4, p. 2046-2056, dez., 2019. E-ISSN: $1982-5587$. 
Conquanto os primeiros ensaios de avaliação externa e em larga escala tenham se consolidado em meados da década de 1990, a gênese do modelo atual pode ser localizada na terceira edição do SAEB em 1995, por apresentar mudanças que alinharam a experiência brasileira com as diretrizes do Banco Mundial. Segundo Lopes (2007, p. 325), a partir desse momento "[...] o MEC fortalece seu papel de formulação e controle. Dentre as principais transformações, destaca-se a criação do Banco Nacional de Itens, a adoção da metodologia da Teoria de Resposta ao Item (TRI) e a terceirização dos procedimentos para realização das provas"; essas características permanecem nas avaliações nacionais na atualidade, sendo que este modelo foi disseminado como padrão nos sistemas estaduais (PERBONI, 2016) e nos sistemas municipais de educação básica (SOUSA; PIMENTA; MACHADO, 2012).

Uma das questões que motivaram esta pesquisa é justamente o motivo que levou os sistemas estaduais e municipais a implementarem processos próprios de avaliação, que tecnicamente seguem os mesmos moldes do SAEB, inclusive, sete estados criaram até mesmo índices próprios de desempenho calculados com os mesmos parâmetros usados para o Índice de Desenvolvimento da Educação Básica (IDEB). Este excesso de avaliações dificulta até mesmo uma análise qualitativa dos resultados encontrados; são tantas avaliações que os professores não conseguem discutir os resultados e repensar a sua prática a fim de melhorar o nível de aprendizagem dos estudantes. Desta forma, a "obsessão avaliativa" nos afasta de uma educação emancipatória: para Adorno (1995), uma das tarefas básicas da educação é impedir que Auschwitz aconteça novamente.

Uma sociedade que valoriza tais avaliações e as considera como medida de qualidade está longe de propiciar a sua própria autorreflexão, o que é vital numa educação emancipatória; a severidade da avaliação, muitas vezes associada à punição, nos remete a um modelo educacional regido pela força e pelo medo: tais recursos geram apenas o conformismo ou ainda "uma consciência coisificada" (ADORNO, 1995, p. 05), na qual uma escola compete com a outra, um professor compete com o outro e ninguém consegue perceber os objetivos reais da educação; tais objetivos passam a ser obter uma nota boa numa avaliação.

Neste contexto, a nossa sociedade justifica a criação de inúmeras avaliações. Podemos destacar ao menos três delas: a possibilidade de maior controle sobre o processo, com aplicação de provas anuais e resultados mais ágeis, a criação de uma pretensa "cultura de avaliação" entre as escolas e a melhoria da qualidade do ensino.

Sobre os dois últimos pontos, deve-se considerar que as avaliações não podem criar uma nova cultura de avaliação, uma vez que as escolas possuem processos consolidados de avaliação da aprendizagem dos estudantes. Ao contrário, neste campo, as avaliações reforçam as RIAEE - Revista Ibero-Americana de Estudos em Educação, Araraquara, v. 14, n. esp. 4, p. 2046-2056, dez., 2019. E-ISSN: 1982-5587. DOI: https://doi.org/10.21723/riaee.v14iesp.4.12927 
características negativas das práticas avaliativas, como seu caráter meramente classificatório, excludente e pontual.

Em relação à qualidade, denota-se que as avaliações a promovem a partir de uma perspectiva restrita e instrumental, que se resume à proficiência dos alunos em português e matemática, desconsiderando nesta medida todos os outros aspectos que podem ser atribuídos como funções da educação escolar. Essa é reforçada por medidas que vinculam os resultados das avaliações às premiações às escolas e à bonificação dos funcionários da educação.

Nenhuma destas razões remete a uma educação emancipatória, para Adorno (1995, p. 144), ela teria "[...] muito mais a tarefa de fortalecer a resistência do que fortalecer a adaptação", desta forma, cabe à Educação suscitar a reflexão e o esclarecimento, para que o indivíduo não permita uma nova barbárie na nossa sociedade; embora o autor não use o termo "qualidade", é possível inferir que uma educação de qualidade para ele não pode ser medida por uma avaliação externa.

\section{Considerações finais}

Ao considerar o conceito de qualidade como um termo polissêmico, Enguita (1995) reforça que em determinados contextos, uma concepção de qualidade adquire prevalência sobre outras. Contudo, não implica na extinção das concepções anteriores, pois cada nova perspectiva sobre a qualidade não substitui inteiramente as que a antecederam.

Esta definição abrange a contento o momento atual em que vivemos. Observa-se a convivência, de um lado, de uma perspectiva de qualidade educacional marcadamente associada ao que é defendido como ideal pela teoria crítica, uma educação emancipadora e crítica, capaz de formar cidadãos críticos e inseridos na vida política e econômica do país. Essa perspectiva de qualidade da educação está contemplada em nossa legislação e igualmente presente na síntese da defesa de uma qualidade socialmente referenciada, formulada no bojo das conferências nacionais de educação e também incorporada em normativos nacionais.

Paralelamente, outra perspectiva de qualidade educacional, contendo uma visão muito diversa sobre o ideal de educação, caracterizada marcadamente como instrumental e pragmática, voltada para a adaptação dos sujeitos aos ditames do mundo capitalista, sem preocupações com a crítica ou com a reflexão sobre os motivos de determinada realidade. Esta concepção está igualmente presente em alguns normativos nacionais como, por exemplo, no Plano Nacional de Educação (2014-2024), sobretudo em sua meta sete, que coaduna "fomentar 
a qualidade da educação básica em todas as etapas e modalidades", atrelando essa a médias nacionais do IDEB.

Entre essas duas concepções de qualidade diametralmente opostas, poderíamos identificar outras, entretanto para os objetivos aqui propostos esse aprofundamento não se faz necessário. Cabe a constatação que a disseminação das avaliações externas e em larga escala, nos moldes propostos nas últimas décadas, tem reforçado fortemente a segunda concepção de qualidade, deixando relegado a um segundo plano outras perspectivas que se propõem a pensar a qualidade educacional de uma forma mais ampla. A concepção de qualidade defendida pelas avaliações em larga escala não representa o ideal de educação presente na teoria crítica; segundo Adorno, a superioridade do homem está no saber, no conhecimento, este não reconhece barreiras, não aceita a escravidão de um homem, nesta perspectiva, a única forma de emancipação humana é através do conhecimento que não poderá ser medido através de uma avaliação externa.

Considera-se, portanto, que os referencias da teoria crítica podem fornecer uma chave interpretativa interessante para esse fenômeno e, igualmente, propiciar oportunidade de reflexões que se contrapõem à concepção, cada dia mais presente, de uma qualidade educacional esvaziada de reflexões e criticidade.

\section{REFERÊNCIAS}

ADORNO, T. W. Educação e emancipação. São Paulo: Paz \& Terra, 1995.

ADORNO, T. W. Educação após Auschwitz. Educação e emancipação, v. 3, p. 119-138, 1995.

ADORNO, T. W.; HORKHEIMER, M. Dialética do Esclarecimento. Tradução de Guido Antônio de Almeida, Rio de Janeiro, Zahar Editores, 1985

AFONSO, N. Estado, políticas educacionais e obsessão avaliativa. Contrapontos, Itajaí, v. 7, n. 1, p. 11-22, jan./abr., 2007.

ALAVARSE, O. M.; MACHADO, C.; ARCAS, P. H. Articulação entre qualidade e gestão da educação: as avaliações externas dos estados em questão. 37 ${ }^{\mathbf{a}}$ Reunião Nacional da ANPEd, 2015, UFSC. Disponível em: http://37reuniao.anped.org.br/wpcontent/uploads/2015/02/Trabalho-GT05-4481.pdf. Acesso em: 13 ago. 2015.

BAUER, A. Estudos sobre Sistemas de Avaliação Educacional no Brasil: um retrato em preto e branco. Revista @mbiente educação, v. 5, n. 1. p. 7-31, jan./jun., 2012. 
BAUER, A.; PIMENTA, C. O.; HORTA NETO, J.; SOUSA, S. Z. L. Avaliação em larga escala em municípios brasileiros: o que dizem os números? Estudos em Avaliação Educacional, FCC. v. 26, n. 62. maio/ago., 2015.

BAUER, A.; REIS, A. T. Base de Dados Avaliação: balanço da produção teórica sobre avaliação de sistemas educacionais no Brasil: 1988 a 2011. São Paulo: Fundação Carlos Chagas, 2014. Disponível em: http://acervo.fcc.org.br.

DOURADO, L. F.; OLIVEIRA, J. F. A qualidade da educação: perspectivas e desafios. Caderno Cedes, Campinas, v. 29, n. 78, p. 201-215, maio/ago. 2009.

ENGUITA, M. O discurso da qualidade e a qualidade do discurso. In: GENTILI, P.; SILVA, T. T. (Org.). Neoliberalismo, qualidade total e educação. 2. ed. Petrópolis: Vozes, p. 93110, 1995.

FREITAS, D. N. T. de. A avaliação da educação básica no Brasil. Campinas. Autores Associados, 2007.

FREITAS, L. C. A Avaliação e as reformas dos anos de 1990, novas formas de exclusão, velhas formas de subordinação. Revista Educação e Sociedade, v. 25, n. 86, 2004. Disponível em: http://redalyc.uaemex.mx/src/inicio/ArtPdfRed.jsp?iCve=873137180008. Acesso em: 05 abr. 2012.

GIL, C. A. Como elaborar projetos de pesquisa. 5. ed. São Paulo: Atlas, 2010.

GOMES, L. R. Teoria Crítica e Educação Política em Theodor Adorno. Revista HISTEDBR On-line, Campinas, n. 39, p. 286-296, set. 2010.

LOPES, V. V. Cartografia da Avaliação Educacional no Brasil. Tese. (Doutorado em Educação) Faculdade de Educação, USP, São Paulo, 2007.

MAAR, W. L. Adorno, semiformação e educação. Educação e Sociedade, Campinas, v. 24, n. 83, p. 459-476, ago. 2003.

MARTINS, A. M.; SOUSA, S. Z. L. de. A produção científica sobre avaliação educacional e gestão de sistemas e de escolas: o campo da questão entre 2000 e 2008 . Ensaio: avaliação de políticas públicas educacionais, Rio de Janeiro, v. 20, n. 74, p. 9-26, jan./mar., 2012.

NEAVE, G. On the cultivation of quality, efficiency and enterprise: an overview of recent trends in higher education in Western Europe, 1986-1988. European Journal of Education, v. 23, n. 1/2, p. 7-23, 1988.

NOBRE, M. A Teoria Crítica. Rio de Janeiro: Jorge Zahar Editor, 2004.

PERBONI, F. Avaliações externas e em larga escala nas Redes de Educação Básica dos Estados Brasileiros. 2016. 268f. Tese (Doutorado em Educação) - Faculdade de Ciências e Tecnologia, Universidade Estadual Paulista, Presidente Prudente - SP. 2016. 
PERBONI, F.; MILITÃO, A. N.; DI GIORGI, C. A. Garboggini. Manifestações do "quasemercado" nas avaliações externas e em larga escala. Educação (UFSM), v. 44, Publicação Contínua, 2019.

ROTHEN, J. C.; TAVARES, M. das G. M.; SANTANA, A. C. M. O Discurso da qualidade em periódicos internacionais e nacionais: uma análise crítica. Revista Educação em Questão (Online), v. 51, p. 251-273, 2015. Disponível em:

https://periodicos.ufrn.br/educacaoemquestao/article/view/7179.

SILVA, I. M. da. A Discussão sobre Avaliação nas Reuniões Anuais da ANPED no Período 2000 a 2010. Avaliação, Campinas; Sorocaba, SP, v. 18, n. 2, p. 335-350, jul., 2013.

SOUSA, S. Z. L. de; OLIVEIRA, R. P. Sistemas estaduais de avaliação: uso dos resultados, implicações e tendências. Cadernos de Pesquisa, v. 40, n. 141, p. 793-822, set./dez. 2010.

SOUSA, S. Z.; PIMENTA, C. O.; MACHADO, C. Avaliação e gestão municipal da educação. Estudo e Avaliação Educacional, São Paulo, v. 23, n. 53, p. 14-36, set/dez. 2012.

SVERDLICK, I. ¿Que hay de nuevo en avaluación educativa? Buenos Aires: Noveduc Libros, 2012.

WERLE, F. O. C. Avaliação em Larga Escala: questões polêmicas. Brasília: Liber Livros, 2012 .

\section{Como referenciar este artigo}

MILITÃO, Andréia Nunes; SANTANA, Andréia da Cunha Malheiros; PERBONI, Fábio. A expansão dos sistemas avaliativos e a teoria crítica: um diálogo (im) pertinente. Revista IberoAmericana de Estudos em Educação, Araraquara, v. 14, n. esp. 4, p. 2046-2056, dez., 2019. E-ISSN: 1982-5587. DOI: https://doi.org/10.21723/riaee.v14iesp.4.12927

Data de submissão: $25 / 06 / 2019$

Data de aceite: 20/06/2019

Data de publicação: 01/09/2019 